\title{
Evolución de las geomembranas de PVC-P instaladas en las bal- sas de la Isla de Tenerife. Importancia de los plastificantes en la vida útil de la geomembrana.
}

\author{
Vara Mora, Tatiana ${ }^{1}$, Cabrera Romero, M Dolores $^{1}{ }^{1}$, Solera Martínez, Rosario ${ }^{2}$, Mateo Sanz, Beatriz \\ 1 EPEL BALTEN; t.vara@balten.es \\ 2 Laboratorio Central de Estructuras y Materiales, CEDEX; Rosario.Solera@cedex.es
}

Resumen: En los años 80 del siglo XX, el Excmo. Cabildo Insular de Tenerife promovió las dos grandes iniciativas de carácter hidráulico que se desarrollaron en la Isla: el "Plan de Balsas del Norte de Tenerife (1980-1990)" con la construcción de 10 balsas en la vertiente norte de la isla y el "Programa de Reutilización de las aguas depuradas de las ciudades de Santa Cruz y La Laguna (1984-1994)", con la construcción de 2 balsas y $70 \mathrm{~km}$ de conducciones de impulsión y transporte en la vertiente sur y 1 balsa y $12 \mathrm{~km}$ de conducciones en vertiente norte. El éxito de este Plan de Balsas dió pie a la construcción de más balsas para poder cubrir las necesidades hídricas de la isla, contando en actualidad con un total de 21 balsas gestionadas por la EPEL BALTEN. Desde noviembre de 1989 se vienen realizando ensayos en las geomembranas instaladas en los embalses de Tenerife conforme al convenio suscrito con el Laboratorio Central de Estructuras y Materiales (CEDEX). la superficie impermeabilizada con láminas de PVC-P. asciende al 62,41\%. En este trabajo se exponen los comportamientos de las distintas geomembranas de PVC-P instaladas en las balsas de Tenerife. Se contrastan geomembranas con la misma formulación pero situadas con distintas condiciones de radiación solar, humedad y tensiones soportadas para comprobar que la formulación tiene un efecto significativo sobre el comportamiento de la degradación de la geomembrana, especialmente a largo plazo. Ya que los Plastificantes son aditivos que se incorporan a la geomembrana de PVC para darle flexibilidad, por lo que su pérdida ocasiona una rigidez en el material, haciéndolo quebradizo. La naturaleza de estos plastificantes es determinante para la vida útil o durabilidad de la geomembrana.

Palabras clave: impermeabilización; geomembrana PVC-P, balsas, plastificantes. 